Article

\title{
Communities of Darkness? Users and Uses of Anti-System Alternative Media between Audience and Community
}

\author{
Christian Schwarzenegger \\ Department of Media, Knowledge and Communication, University of Augsburg, 86159 Augsburg, Germany; \\ E-Mail: christian.schwarzenegger@phil.uni-augsburg.de
}

Submitted: 30 June 2020 | Accepted: 5 September 2020 | Published: 3 February 2021

\begin{abstract}
The hopes regarding the positive impact of the Internet and digital participation in civic society have faded in recent years. The digital realm is now increasingly discussed regarding its role in putting democracy in jeopardy and polarizing public debate by propagating extremist views and falsehoods. Likewise, the perception of so-called alternative media as beneficial carriers of counter-public spheres and as important complements to mainstream positions in social debate has flipped. Alternative media are now often associated with the "Wicked web" of disinformation, political populism, or even radicalization. Following Quandt's (2018) notion of 'dark participation' and Phillips and Milner's (2017) description of the Internet as ambivalent, this article asks, whether the same holds true for the users of alternative media: a segment of the audience traditionally discussed in terms of community, engagement, participation, and strong ideological identification with progressive political causes. Do users of 'dark' alternative media bond with their media in similar ways to constitute communities of darkness? Based on interviews with 35 users of alternative media from a left-leaning, right-wing, Russian-tied and/or conspiracy spectrum users, uses of alternative media are pictured as grey rather than black or white. The findings illuminate the ambivalences within alternative media users as audiences and communities. Ambivalences are found regarding the use of alternative sources as audience or community members, regarding a shared attitude of criticality and anti-systemness, which connects trans-medially and trans-ideologically, as well as the experienced comfort of community, which can become a main motivation for use.
\end{abstract}

\section{Keywords}

alternative media; anti-system; audience; community; dark participation; populism

Issue

This article is part of the issue "Dark Participation in Online Communication: The World of the Wicked Web" edited by Thorsten Quandt (University of Münster, Germany).

(C) 2021 by the author; licensee Cogitatio (Lisbon, Portugal). This article is licensed under a Creative Commons Attribution 4.0 International License (CC BY).

\section{Introduction: Into Darkness}

The tide has turned. The high hopes regarding the positive impact of the Internet and digital participation in civic society have faded over the last couple of years. We do live in times 'after the hype' (Kaun \& Uldam, 2017) and optimistic aspirations that democracy would be enhanced by the blooming of social movements and digital media activism, allegedly enabled by the Internet, have sobered. The digital realm is now increasingly discussed in terms of its role in putting democracy in jeopardy and polarizing public debate by propagating extremist views and falsehoods. The dark side of digital media technologies is that they can also be means of suppression rather than tools for empowerment (Treré, 2016). Likewise, the perception of so-called alternative media as beneficial carriers of counter-public spheres giving voice to minority positions and critique as important correctives to mainstream positions in social debate has flipped. Previously romanticized oases of voice and deliberation providing a fresh breeze for democratic progress are now suspected to represent foul swamps of disinformation ecologies, vile tools for political agitation, or even drivers of radicalization.

But with alternative media now increasingly being discussed in the nexus of populist or extremist politics 
(Holt, 2020) and regarding political agitation, disinformation dissemination, and its allowing propaganda to bypass the checks and balances of professional journalism, what does this reveal about their audiences? Traditionally, these users-a gravely under-researched and hardly known species-have been discussed in terms of community, engagement, participation, and their high levels of identification with alternative media products. When alternative media are considered tools for ill intent, does this suggest that their users are shrouded by darkness? And do they knowingly or unknowingly support vile causes through their participation? This article investigates the users, user communities, and usage of alternative media to better comprehend their relationship with sinister goals and anti-democratic tendencies.

Quandt (2018, p. 44) when proposing his concept of 'dark participation' emphasized that although there "is a large variety of participation behaviours that are evil, malevolent, and destructive," the future of digital communication "is not all doom and gloom," as the past was not all bright. By "adding some black to the pearly-white idealism of citizen engagement" (Quandt, 2018, p. 37) in digital contexts, one "might end up with a more appropriate grey," instead of the high hopes or sombre sorrows concerning the digital realm's role for democracy and communication. Other authors have also contributed to the "deconstruction of earlier, naïve ideas" (Quandt, 2018 , p. 37) regarding the web as a happy place for the betterment of society. Phillips (2015) argues that malignant online practices, e.g., trolling, widely condemned as obscene and deviant, are not that deviant but must be understood as integral elements of digital culture, supported and nourished by a responsive environment. In this sense, practices may arguably be offensive, weird or obscene, but they are 'normal' and a characteristic of the online ecosystem nonetheless. Phillips and Milner $(2017$, p. 5) describe the Internet as ambivalent, and argue that digital communication practices can be "simultaneously antagonistic and social, creative and disruptive, humorous and barbed, [and hence] are too unwieldy, too variable across specific cases, to be essentialized as this as opposed to that." Considering digital culture as ambivalent "collapses and complicates binaries within a given tradition" (Phillips \& Milner, 2017, p. 11), e.g., between alternative and mainstream, abhorrent and admirable, odd and normal, light and dark participation.

In order to approach users and user communities around alternative media, the article first provides a glimpse at the rich history of competing understandings of alternative media and impeding characteristics and features. This is followed by addressing the profound lack of research into the audiences and users of alternative media and discussing the little knowledge we have about it. Then, the findings of an exploratory and theorygenerating interview study with users of "dark alternative media" are presented. The results aim to highlight that the users of alternative media cannot simply be classified based on the orientation or content of the plat- forms they tend to use, rather, their motives, practices, and identification with the alternative media are varied and ambivalent.

\section{Alternative Media and Their Respective Mainstreams}

There is a lot of 'conceptual confusion' (Holt, 2020) around the notion of alternative media, and we can look back on decades of rich debate on what constitutes alternative media and in how far they pose alternatives to exactly what. "Endless discussions about its key features and practices" (Hájek \& Carpentier, 2015, p. 365) in academia have reinforced a conceptual binary between alternatives and their respective mainstream counterparts. The notion of 'alternative' implies that it must be a complementary, substitutional, additional, or simply different version to something else. As Holt, Ustad Figenschou, and Frischlich (2019) have described, the active positioning of so-called alternative media vis-à-vis an alleged mainstream is a key dimension for approaching and understanding alternative news media. Instead, this juxtaposition is also crucial for identity management and self-perception of (some) alternative media outlets, which feast on their status as a corrective or even as being an explicit opposition to the mainstream, including purportedly one-sided or incomplete representations of social reality proposed by legacy media (Figenschou \& Ihlebæk, 2019; Holt, 2019). Furthermore, nurturing such a collocation of alternative and mainstream as opposing blocks, can also contribute to essentializing either side as uniform and suggest homogeneity and negate actual diversity and pluralism in the discussed area.

To help dissolve the binary between mainstream and alternative and find a more nuanced and sensitive understanding of the notion, Downing (2001) preferred to speak of alternative media with a dedicated political agenda as radical media. He described such radical media as being "generally small-scale and coming in many different forms, but with the common characteristic of presenting, proposing and providing alternative visions to hegemonic policies, priorities and perspectives" (Downing, 2001, pp. v). While Downing foregrounded the political and 'resistance potential,' Atton (2002) in his take, emphasized a broader understanding of their transformative potential as a key characteristic of radical alternative media. The transformative potential can also extend beyond more narrow political contexts. Also, Fuchs has emphasized the potential of alternative media to resist and reform, when he modelled them as critical media (Fuchs, 2010). For Fuchs, alternative media as critical media question domination, express the positions of the oppressed, and dispute "for the advancement of a co-operative society" (Fuchs, 2010). Alternative media has traditionally been seen as associated with the progressive left and somewhat idealized by scholarship (Holt et al., 2019). This development was historically consistent with the hopes 
and expectations regarding the democratic potential of digital participatory culture of the coming Internet.

'Alternative media in the service of repression' (Downing, 2001), on the contrary, were rather sidelined or neglected. While their existence and perilous potential were acknowledged, they mostly remained out of focus, and 'rebellious media,' fighting for more positively perceived causes in the reform of culture and society were brought to the mainstage of scholarship. In recent years, this has (slightly) changed and the other alternatives (Atton, 2006), typically depicted as darker alternatives to their positive counterparts, became more prominent in research (Haller, Holt, \& de la Brosse, 2019). These darker alternatives are alternative media, which are often described as linked to political extremes, mostly far-right populism (Holt, 2019), to conspiracy theorists, or having ties to Russia. Instead of a potential, they are regarded as a peril for democracy and this recent research on alternative media has emphasized their role in the spread of disinformation and as drivers of political polarization or even radicalization. Studies on alternative media are hence likely to actually speak of very diverse phenomena using a similar vocabulary. Some authors such as Hájek and Carpentier (2015) hence advocate that media theory should better protect the 'alternative media signifier' against being too widely applied, lest it also be applied to those who have simply claimed the alternative label for themselves and who do not meet the requirements and features to be defined as such.

The apparent diversity of alternative media and the many versions of what they can be alternatives to suggest considering alternative and mainstream as a shifting continuum rather than absolute categories (Holt et al., 2019; Kenix, 2011; Rauch, 2016). For instance, based on her analysis of audience's understandings of the mainstream alternative dialectic, Rauch (2015) has described-similar to others (e.g., Atton, 2002)-how being an alternative can either relate to the product or the process. She speaks of organizational alternatives (for instance amateurism vs. professionalism, commercialism vs. non-commercial orientation) or of content alternatives (offering other views, other topics, voicing critique). With changing media landscapes, changing political systems, and evolving public debates, what is alternative at one point can become mainstream and vice versa (Kenix, 2011, p. 17). Holt et al. (2019) argue that alternative and mainstream hence must be interpreted as strictly contextual and relational. Speaking of alternative or mainstream then only makes sense 'in regard to' something:

By considering alternative news media as an "alternative" and "in regard" to-allows to put them into context. It accommodates alternative news media inspired by diverse political (left as well as right wing), religious (e.g., fundamentalist or extreme liberal) or philosophical (e.g., animal rights) ideologies that outspokenly describe themselves as counter- hegemonic correctives to mainstream news media or are described as such by their audience or third parties. (Holt et al., 2019, p. 866)

I will follow this relational understanding and focus on such alternative media, typically regarded as dark alternatives, which are alternative regarding their political position and characterized by what Holt (2018) speaks of as anti-systemness. These alternative media outlets position themselves as opposed to the alleged mainstream media, which are regarded as representatives of the system and hence accomplices to the political establishment, distorting or concealing reality for their interest (and against the manipulated people). Such a kind of anti-systemness, combined with an anti-elitist and antiestablishment attitude has also been identified as a characteristic feature of populism (Krämer, 2018; Mazzoleni, 2008). Anti-systemness, however, is not necessarily populist, and traditionally alternative media as carriers of counter-public spheres have also featured this stance. Like alternative media, counter-public spheres (Fenton \& Downey, 2003) also have a history of being romanticized in media and communication scholarship as inherently progressive and pro-democratic.

The anti-system stance supports the idea that alternative media platforms can blend well with populist politics and provide mutual sustenance (Holt, 2020). These media "do not have to follow commercial logic, journalistic conventions, or ethical principles: they can be as radical and polemical as they wish" (Noppari, Hiltunen, \& Ahva, 2019, p. 26). A lack of commercial orientation has traditionally been seen as a characteristic of alternative media. However, not following journalistic conventions and being highly polemic and polarizing as well as partisan can also be part of a flourishing business model. Right-wing platforms such as Breitbart and InfoWars in the US; the Austrian unzensuriert, and the German KenFM espouse their alternative (political) views with ideological as well as financial interests.

Additionally, alternative media platforms can be attractive for users susceptible to political populism. For instance, studies have shown that alternative media are strongly featured and referenced in the (social media) communication by populist political actors (Bachl, 2018). Several studies have found similar strong links and mutual referencing between alternative media platforms and populist political parties or populist politicians (Haller \& Holt, 2019). Yet, while new alternative media in the digital realm can cater to problematic causes and help pursue darker political goals, this cannot automatically be assumed for their users. The audience and users of alternative media remain widely unknown.

\section{In Search of the Virtually Unknown-The Audiences and Users of Alternative Media}

17 years ago, Downing (2003, p. 625) argued that there was "a distinctly disturbing gulf between our currently 
fragmentary knowledge or debates concerning how audiences and readers use alternative media" in comparison to "the mass of descriptions and theorizations of alternative media," their potential impact and their role for social movements or in critical counter-public spheres. Back then, he described the research into audiences and usage of the myriad and ever-growing numbers and outlets within the alternative media spectrum as a "minimally developed" area of research. The "virtual absence" (Downing, 2003, p. 626) of audiences and users has since not changed drastically and audiences still remain the neglected foster child of research into alternative media. For instance, among the 50 chapters in the Routledge Companion to Alternative and Community Media (Atton, 2015), not one is specifically dedicated to the audience of alternative news media. There is, however, a section on the communities and identities, which form around the practices of producing, contributing to, and being part of an alternative news media cosmos. Especially with alternative media associated with or linked to particular social movements, people in the vicinity of alternative media are regarded as part of distinct or amorphic activist groups constituting interpretive communities' (Rauch, 2007), rather than news audiences. But the people who are served by and use alternative media, mostly remain out of the picture.

Especially regarding the users of the aforementioned darker alternatives, Noppari et al. (2019, p. 24) note that their users "have stereotypically been labelled as misguided and as having insufficient media literacy." The authors further see such characterizations as being mostly based on assumptions, as little empirical research has been done on users (and producers) of such media offerings. One of the rare exceptions is provided by Müller and Schulz (2019, p. 3) who also describe research on the users of alternative media as "scarce." In their own take on the audiences of "alternative media with an affinity for populism," Müller and Schulz (2019) focused on political attitudes and patterns of media use as predictors for the likeliness of exposure to alternative media. While they differentiated between occasional and frequent, recurring users of alternative media, details of how people make use of alternative sources and how this might play out in their media use or media repertoire over time, were not under scrutiny.

A study that looked more closely into the how and why of using alternative media platforms, or as they call them 'counter-media,' was presented by Noppari et al. (2019). Based on their interviews with users of Finnish right-wing alternative media platforms, they distinguish three different types of users. According to them, system sceptics, as a first type, can be described as societal outsiders, with strong political or ideological beliefs. This type of users shows high hopes into the counterpublic sphere in which they actively participate and hope for a change of the system. They often actively support the alternative media they consume or try to share their views on their own social media profiles. Instead of being generally sceptical, the distrust and scepticism of the second type, agenda critics, was aimed at specific topics, in which they believed legacy media would push its own particular agenda and be hostile to their personal opinions. This type of user would share alternative media content and often belong to social media groups around them. For the first and second type, active contribution and association with the alternative media they use were relevant. The third type, the casually discontent, are critical of certain journalists or topics and seek alternative positions in alternative media but use them only sporadically. They did not show ideological commitment to the partisan alternative media but rather were characterized by what the authors call savvy scepticism and constant irony. A crucial takeaway from this study is that for dedicated users, seeking contact to and comfort in a community of likeminded people was fundamental. Antagonism against legacy media and their allegedly lopsided agenda was a vital building block of community efforts.

Particularly in today's high-choice digital media environments, fresh contact and first-time exposure to alternative media outlets can easily occur incidentally and without further intention or attention of wouldbe users. Due to algorithmic curation of content selection and content presentation, follow-up interaction can become more likely after the initial contact with a particular source (O'Callaghan, Greene, Conway, Carthy, \& Cunningham, 2015). Initial contact can play a role in the process of red pilling, i.e., making fresh contact with alternative news media and then being attracted into a sphere of increasingly extremist content. Red pilling, as Marwick and Lewis (2017) describe, often begins with contact to a content which appears attractive (a topic, an idea they can identify with, or a style of presentation, e.g., dark humour) and eventually spreads from there. However, people who occasionally have contact with alternative media platforms are not automatically drawn into a spiral of radicalization (Munn, 2019).

The argument that people who do distrust legacy news media are likely to refrain from accessing alternative news sources and search for alternative and allegedly independent sources has been supported by multiple authors at different times (e.g., Jackob, 2010; Newman, Fletcher, Kalogeropoulos, Levy, \& Nielsen, 2018); albeit with broad and diverse understandings of alternative media. According to Leung and Lee (2014), using Social Networking Sites for the purpose of news consumption is strongly related to coming across alternative media and being exposed to their content. Users in social media settings often struggle to differentiate the trash from the treasure and to identify the valuable or reliable sources from the dubious (Edgerly, 2017; Schwarzenegger, 2020; Tandoc et al., 2017); strategies of news authentication or verification tend to be either unsuccessful or pursued only until users' pre-existing assumptions about a topic are confirmed. In an exploratory study, Schwarzenegger (2020) compared digital news navigation and information verification strategies of users of alternative media 
with non-users. He found that users of alternative media, in particular, made paradoxical calls for unbiased reporting and perceived legacy media coverage as biased or not neutral. They also thought highly of themselves as critical thinkers and competent at detecting wrong information as well as balancing the biases, when using alternative media as complementary sources. While they typically pictured themselves as sceptical against all sides, their media practices revealed that they were highly selective in their criticality and did not doubt alternative sources in the same way as legacy media.

As mentioned above, the users of alternative media are often rather discussed with regards to community building and identity work (see respective chapters in Atton, 2015) than in terms of audience research. Alternative media, like other digital communities in general, can become ideological touchstones for their users and provide them with a sense of belonging and community (Rauch, 2007) which might have a particular allure for those considered as 'societal outsiders' elsewhere. While the foundation for this sense of belonging can be found in ideological beliefs or coherent worldviews, the appeal of an online community can also be based on shared practices or expectations. For instance, Topinka (2018) described how users can sustain communities based on their shared sense of a twisted and somewhat abusive humour and the lustful breach of societal taboos. In this trajectory users of alternative media platforms can also find comfort by perceiving themselves as members of (at least loosely connected) collectives rather than being alone. Whether it is the political direction of the content, the support of being sceptical together, or the thrill of following something that is deemed harmful in the public eye is an empirical question. The community perspective can be beneficial for understanding what attracts users to alternative media and how users socialize and bond (both online and offline) even if they do not fully identify with media ideologically. But as Dagron (2007) has criticized, the image of alternative media communication as small, isolated, and pure forms of community communication does not correspond to reality anymore, if it ever did. Following Postill (2008), the dominant role of community as the all-encompassing gaze on users of activist and alternative online media can obscure the fact that the uses can be impure (Dagron, 2007) and ambivalent or casual and incidental. Digitalization has supported an unprecedented increase in news media platforms, by legacy media and alternative sources alike. In high-choice media environments, alternative media can become part of a media repertoire without their users even being aware of or giving weight to their alternativeness, as they encounter them embedded in social media environments, as they do with legacy media. In this sense, not assuming that users of alternative media can be classified as a close community of likeminded people, but discussing them in terms of audiences, "as the people who, in their capacity as social actors, are attending to, negotiating the meaning of, and sometimes participating in the multimodal processes initiated or carried out by institutional media" (Schrøder, 2019, p. 160). Audiences are typically researched regarding their motives and criteria regarding selection and interpretation of media and its contents. Hence, applying an audience perspective on alternative media users can help to unravel the granular motives and uses as well as the 'nuanced gratifications' (Sundar \& Limperos, 2013) that can be found in the use of alternative media.

\section{Method}

This article is based on 35 guided interviews with users of alternative media. Alternative media titles were generally differentiated as left-leaning, right-wing, Russian-tied, or as belonging to the conspiracy/esoteric spectrum based on previous research (e.g., Bachl, 2018; Schweiger, 2017) which guided the recruitment of participants. Interviews were conducted with German, Austrian, and Suisse alternative media users (aged 22 to 63) in 2019 by the author and a team of student assistants in a research seminar; the analysis was performed by the author alone. The interviews were semi-structured and conversational, lasting between 43 and 113 minutes. Most interviews took place face-to-face, some via Skype. With permission, each interview was digitally recorded in its entirety and transcribed subsequently. Pseudonyms have been used for quoted material to protect the privacy of participants. The recruitment process for the study was organised in both consecutive and parallel steps. First, a series of media outlets related to the four different camps discussed here were included based on the previous research, self-positioning of the media, and public debate. The left-leaning outlets included NachDenkSeiten and Rubikon; the rightwing outlets comprised, for example, Compact and PI-News; the Russian-tied outlets contained, among others, RT Deutsch and Sputnik News; and the outlets belonging to the conspiracy/esoteric spectrum were e.g., KenFM and kla.tv. In a second consecutive step, users of these outlets were identified and contacted in two ways: Student assistants in the research seminar functioned as 'mediators' (Kristensen \& Ravn, 2015), and were asked if they knew someone who was a dedicated, visible, or self-declared user of the identified alternative media outlets. Additionally, active users on the alternative media outlets' social media sites were identified based on their online practices and participation in the online comment sections and contacted via the respective social media channels. This was difficult, as the effort to make contact would often be filtered out, simply not seen, or wilfully ignored. As a third and complementary strategy, we followed a snowball principle (Goodman, 2011), asking interview partners who were already participating in the study whether they could recommend other users they knew who might be interested in participating in the study. The final sample included 
users from different countries, which is rather an effect of a shared German-speaking mediascape and transnational connectivities among alternative media users. For instance, RT and Sputnik in their German versions cater to the different countries. Austrian right-wing alternative media find some resonance among German users (e.g., unzensuriert, Wochenblick and Alles Roger), whereas right-leaning German platforms are also used and shared in the neighbouring countries. Subjects of the interviews were: Participants' general media use and repertoires in the everyday now, and as remembered, their media ideologies and media beliefs including trust and criticism of the media, and their political orientation. Further, interviews addressed how the respondents initially came in contact with alternative media, and the role played by alternative media outlets for them both in their media repertoire and regarding their general worldview and outlook on (political) issues. Of particular importance in the interviews was the topic of community participation. Hence interviews addressed the question of how far and in which way respondents were partaking in community activities around alternative media and in how far they perceived their online activities as community-related. Data analysis followed a qualitative content analysis coding-scheme and was supported with QDA-Software 44 -analysis. The analysis was guided by the deductive categories reflected in the interview guidelines (e.g., community participation, media ideologies and beliefs), which were applied to the material. In the process of coding, these deductive categories were inductively refined, and additional categories, as well as new subcategories, were introduced whenever new themes and issues emerged in the data. In the last step, the material was coded once again with the final coding scheme and theses were formulated as a result of the coding.

\section{Findings: Users of Alternative Media beyond Dark and Light}

The findings of the study are organized in three theses, each addressing a particular shade of grey and ambivalence among the communities of users and audiences of dark alternative media.

\subsection{1st Ambivalence: Sometimes Users are Just Users and Rather Audience Members Than Community Members}

Users of alternative media-when addressed in research-are typically discussed in terms of identification and community. Following the study presented here, this is important for some, but is far from being relevant to all informants. On the contrary, users of all types of alternative sources in the research spectrum expressed that alternative media are one type of sources they turn to, in order to complete their picture or add additional layers to their information spectrum:
In my opinion, no address or source always reports authentically and always brings the facts in the necessary depth. In my opinion there is no such thing. Instead, you have to get the information on the subject from diverse sources. (Ralf, 30)

The search for alternative viewpoints can be motivated by distrust or scepticism towards legacy media. As in previous research, the informants expressed that they frequently find mainstream coverage to be incomplete, biased, and omitting or concealing relevant aspects of the issue, partially to fit their own agenda or, equally important, for commercial interests. Besides political partisanship, blatant sensationalism and poor reporting also deter users. However, scepticism rarely turns into hostility towards the media or reproaches of wilful manipulation.

Rather than being hostile media illiterates, some of the informants display a rather sophisticated understanding of affordances and challenges of news reporting, e.g., time constraints for reporting and limited capacities that demand selection of topics and perspectives presented. Alternative media as news sources are then sometimes sought out as the other part and complementary voices, but without necessarily considering this information more trustworthy or complete. Quite the opposite, some of the users of $R T$ or Sputnik argued that they would, of course, consider these platforms openly biased and driven by Russian agendas. However, as users assumed to know what the biases are, they thought they were able to balance or filter them on reception. Additionally, other media were believed to also carry biases, but in an obscured way. Similar observations could be made with right-wing media platforms, which were sometimes seen as amplifiers of German populist party AfD politics, but users would trust their individual competence to cope with this partisanship. Probably, this is an indicator of users overestimating their capability to verify information and check sources.

An interesting example of the variety of uses and motives that can result in recurrent consumption of alternative media sources is represented by Sabrina, a 53-year-old flight attendant and avid user of right-wing alternative media. She doesn't identify with their political views but recurrently frequents such platforms to check out "what they are up to next" while often thinking "this must be bollocks." Sabrina frequently engages in online-discussions and aims to debunk misinformation and advocate for a civilized discourse among online users. To this end, she wants to know what "the other camp" is currently discussing and sharing, to brace herself for arguments to expect and misinformation that is likely to be referred to in debates. A similar practice could also be observed in a different direction. Some media sceptical alternative users, with low levels of trust in legacy media, would even intensify their use of public service broadcasting news, to unravel "manipulations": "It's not that what they show didn't happen, but as soon as the interpretative framing begins, when they move away 
from plain and simple reporting, there are other powers and interests at play" (Anton, 43).

Although some users will buy into virtually everything the alternative media offers and doubt the mainstream positions with similar intensity, it was quite common that also alternative media were handled with care and distanced scepticism. Informants like electronic engineering student Theodor expressed that they trust legacy media overall, which constitute by far the largest portion of their media diet. Yet, they garnish and complement it with alternative news media. Still, the expectation is that they will only occasionally find an opposing (ideological) counterweight to the mainstream, rather they access such sources for variation and nuance: "One is not necessarily more balanced informed I would say, but more varied..... In any case, you get a larger overview, which address others or concern others or something like that" (Theodor, 26).

Some informants have rather sporadic contact with particular alternative media titles, while others follow them continuously as part of their media repertoires. But, and this is important, some treat them as sources among other sources, neither privileged nor condoned, others rather trust legacy media and use alternative sources for cross-referencing, while others rather believe alternative sources and use them to check and challenge mainstream reporting. Users do not necessarily identify with them but become a-frequently critical, amused, and oppositional-audience.

\subsection{2nd Ambivalence: Alternative Media Users are Diverse but Anti-Systemness Connects Trans-Ideologically and Trans-Medially}

Although informants were recruited based on their use of at least one 'dark' alternative media title, the interviews demonstrate, that users hardly ever remained exclusive users of just one platform. As they reported, the share of alternative media they frequented grew over time. This modification of the composition of media repertoires was partly furthered by digital recommender systems but also following the personal recommendations of other users and online commentators. One informant explains:

It's the thirst for knowledge, the curiosity, that stimulates it and I think understanding. If I may go back to the picture of the puzzle, the puzzle grows exponentially. So it is growing, in comparison, if I only focus on the mainstream media, then I might just have the edge together...through the alternative media and the mixture with the established media, but I also manage to put the inner part together slowly and leisurely and part by part. At least I am convinced of that [laughing]. (Bettina, 38)

The example of Luise (59) demonstrates that the growth of alternative news media rarely follows a clear-cut politi- cal agenda nor happens entrenched in ideologies or political camps. Hence, classifying users as either left-wing or right-wing sympathizers based on the particular platforms they use is problematic. Luise's initial contact with alternative media was with rather esoteric titles, which are also crosscutting (partially cloaked) right-wing narratives. From there, her diet expanded via Facebook and YouTube to include alternative media allocated to the conspiracy and left-leaning spectrum. This pattern was very common, with the committed users of right-wing alternative media being least likely to expand beyond their own segment and the left-leaning and conspiracy titles being most commonly part of a combined diet. Luise's user type represents an ideological bricoleur, taking fragments of different ideological and political camps as long as they fit an overall orientation of discontent, anti-systemness, and critique. The platform KenFm, regarded as a conspiracy platform, was popular with users who would otherwise either prefer left-leaning or right-wing platforms. Also, media with links to Russia were popular across political orientations or did blend with all other types of alternative media in the study. This orientation-dominated use of alternative media outlets became also apparent in users from different countries who could relate to the anti-system reasoning provided by the alternative media and transferred stances to their own particular original political contexts.

In sum, the same alternative media platforms are used by users with a variety of political and ideological orientations and different motivations. At the same time, users with highly different backgrounds and orientations may pick their arguments and pieces of information from the same or similar alternative media outlets. This ideological flexibility was not limited to picking from a wide array of ideologies from alternative media, legacy media content, e.g., public broadcasting satire format Die Anstalt was also highly acclaimed for its antisystemness. These findings foster the importance of media repertoire or media ecology perspectives, which do not analyse particular platforms and their users in isolation, but in a relational perspective, and with regard to the use of other news sources, both legacy and alternative media.

Users of alternative media may cut across different ideological areas and not belong to coherent communities around them, yet still have common attitudes and features. Across all types of alternative media under scrutiny users typically thought of themselves as being very critical media users and critical thinkers in general, better informed and more knowledgeable than regular media audiences and their acquaintances:

Much more critical than others. I notice that in conversations with others. They are clearly less informed than me, they have less general knowledge and yes, but some of them don't want to, they are less interested. I can say that quite clearly, I am obviously more critical than the average. (Michael, 52) 
These third-person effects of users of alternative media, who would consider themselves savvier and more competent to identify disinformation are well in line with previous research. Schwarzenegger (2020) has shown, however, that high confidence in one's competence to make sense of and assess the veracity of information does not necessarily reflect actual skill but may keep users from actively challenging information.

\subsection{3rd Ambivalence: The Comfort of Community Can Outshine Ideologies, Bringing Light to the Darkness}

So far, I have shown that users of dark alternative media do not necessarily convert to a community. But there are also cases in which the cosy experience of belonging and sharing commonalities is crucial, and can become even more important than the alternative news per se. The comfort of not being alone in their scepticism, the feeling of being understood by likeminded people and not considered weirdos, loonies, or conspiracy theorists for their divergent views-an imminent fear of some of the informants-is an illuminating experience for users within their alleged darkness:

You can discuss about everything and you are not looked at crookedly if you have a different opinion about the news from the traditional media. So that you can exchange views and also say that what the other media say is often nonsense. So that you also know that others also recognize this and you are not alone. (Felix, 30)

Some users expressed that they rather refrain from trying to convince others of their alternative views or to openly convert them. Partly, because they want to avoid confrontation or objection, partly because 'waking up' is someone everyone needs to do on their own terms. In this case, participants seek and find support, social interaction, and validation in the social media communities built around alternative media outlets. The significance of the community for individual users is best illustrated by the case of 38-year-old Bettina. She is an avid user of a platform which belongs to the conspiracy spectrum of the sample and is notorious for its anti-systemness. Since Bettina started following this platform and its YouTube channel, she also engaged in their Facebook fan group. The group name indicates it is open 'for system critics' only and Bettina since starting out with a few user-comments she made it to the rank of group administrator. Outside the web, Bettina is a trans-woman. In the interview, she described that since her transition and due to her current personal situation-working lots of night shifts, being alone at work and mostly alone during the days - for her, engaging in online discussions and alternative media related online groups is one of a few "chances to talk to people." Through her personal background, she is sensitive regarding gender-related issues, which she thinks are blatantly addressed badly in mainstream and alternative media alike. In the group, however, she only rarely engages in discussion when "gender stuff" is addressed. Bettina does not want to be "outed" in the group as trans and does not want to endanger her status within the group. At least occasionally, for Bettina, the sense of community and belonging she experiences in the group can outshine the ideology. The personal situation and experience of Bettina is certainly exceptional. But her case is nonetheless a focal glass for other informants' experiences. Peaceful co-existence in like-mindedness is also highlighted as an important community feature by Luise and Marianne, who are also part of an alternative media fan community on Facebook. "It is important that we are on the same page, share similar viewpoints, are on the same level. Neither too far to the left, nor to the right" (Marianne, 62). However, while the demand for non-radical and balanced positions was very common and positions too extreme were considered out of place, it was the users of right-wing alternative media in particular who would object to a qualification of the media outlets they used as far-right, and would rather reframe them as conservative or "how the common people think." They were hence generalizing and normalizing the worldviews they found in these media. Communities provided them with an environment that helped imagine right-wing worldviews as commonsensical.

\section{Conclusions}

Over the last couple of years, a growing interest in alternative media, especially those in the digital realm and catering to an anti-system stance can be observed in media and communication research. However, the notoriously "weak appetite for user research within alternative media" diagnosed by Downing (2003, p. 627) was not stimulated in the same fashion as the general attention for alternative media has increased. This study set out to generate an appetite for further investigative research into audiences and users of allegedly dark alternative media and their communities of darkness.

The findings sketched here suggest that users of alternative media are not a homogenous lot: their practices, motives, and orientations are more nuanced than simply aligning a populist media with a populist audience. However, at this point, this study does not aim to provide a renewed definition of the audience of the wide diversity of platforms and outlets referred to as alternative media. Instead, the empirical part of the study set out to question some purported certainties and to advocate for greater ambivalence when researching users of alternative media. Treré (2020) highlights the potential of recognizing the ambivalent nature of digital media and communication practices. According to him, this does not equal simply acknowledging that technologies can be used for the good or the bad. Instead, it means critically charting the social, cultural, and political conditions under which certain kinds of media practices, technological 
appropriations, and media imaginaries were generated, combined, and implemented by concrete individual and collective actors in specific historical contexts. Thinking of the users of alternative media as both audiences and communities enable the highlighting and foregrounding of particular moments of their engagement with the media in their repertoire, which can be caused by not only various but even contradictory impulses. At the same time, it also prevents hasty universalism based on an overemphasis or neglect of community aspects.

The three theses presented here aimed to illuminate the ambivalences within alternative media audiences and open avenues for future research. First, when alternative media use is not necessarily linked to ideological identification and community participation, but can simply be part of diversified media diets in highchoice media environments, it is important to learn more about the effect and long-term impact that the use of alternative media can have for the composition and interplay of media in media repertoires over time. Second, the findings invite further investigation of the commonalities and differences across alternative media and users from different political camps and ideologies in trans-ideological and transmedial combinations. The cross-references, entanglements, relations, interdependencies, and mutual influences that the use of alternative media has on the media repertoire, the information horizon, and political participation and orientation can only be understood in the long run through a transmedia or media ecology perspective.

This can help prevent claims of exceptionalism and universalism alike. It further helps to understand the potential problematic impact that alternative media and their anti-systemness can have on public discourse at large, beyond the sometimes irrelevant niches in which they circulate and reinforce their positions (Holt, 2020). At the same time, it can help deconstruct superficial views of "pure" users, that qualify them according to their assumed political ideologies, as conspiracy-loons with insufficient media literacy or even prone for radicalization based on an alleged impact the alternative media may have on their users-an overemphasis of effects and identification supported by the community view, which would be considered an overcome position in audience research. Third, the results suggest that the role of belonging and community require further attention. Media literacy programs and initiatives which raise awareness of the perils of online disinformation and propaganda need take into account that fact-checking and literacy can't be effective antidotes when their side effect would be the dissolution of users' important personal social bonds.

As with every kind of self-reported data, one has to be careful about particular elements of the users' accounts. It would be naïve to simply take the selfpresentation as critical thinkers, well informed and openminded citizens equally wary against falsehoods from all sides for granted. Further, it could be said that the find- ings of this study are influenced by the sample composition. In all steps, the recruitment process was tedious and not without setback: Besides a rather typical low response rate when recruiting via social media, several people who were approached as potential participants declined for a variety of research-related reasons. For instance, people feared that the findings would be used to further discredit alternative media, which in the view of some respondents were treated unfairly in public debate. Another line of reasoning when declining to participate can be explained by the anti-system stance described above: University researchers would then be seen as associated with the system if not even representatives of what they saw themselves in opposition to. A third line of decline was due to the EU's General Data Protection Regulation and the requirement to fill in official University forms to express consent, as users did not want to be associated and/or recorded in some cases. In general, the responses of those who actively declined the invitation to participate suggest that those users who were especially highly entrenched in the ideological camps behind the respective alternative media and with a strong anti-systemness were likely not to participate and hence rather moderate users may have been open to contributing to the study.

The lack of political hardliners, the absence of stubborn ideologists and of incompetent media-illiterates may signal too reflexive, too openminded, and too few misguided, ill-informed views. However, there were some of these negatives in the sample, and probably even more so among the users who refused to participate in this study. But at the same time, this limitation is also a main takeaway from the study. Users and uses of alternative media are ambivalent, not a secluded community of darkness, but diverse people with diverse backgrounds and motivations, who happen to use alternative media as part of their media repertoires. They are neither black nor white. There is a whole lot of grey to discover around them.

\section{Acknowledgments}

This research has greatly benefited from the support with recruitment and interviews by the 19 participants of my MA research Seminar 2019 in Augsburg, and my three student assistants Aliscia Albani, Julia Bartsch and Sabrina Zierer. I would also like to thank the Academic Editor and all four anonymous reviews for their meticulous feedback and rich suggestions in finalizing this article.

\section{Conflict of Interests}

The author declares no conflict of interests.

\section{References}

Atton, C. (2002). Alternative media. London and Thousand Oaks, CA: Sage. 
Atton, C. (2006). Far-right media on the Internet: Culture, discourse and power. New Media \& Society, 8(4), 573-587. https://doi.org/10.1177/1461444806 065653

Atton, C. (Ed.). (2015). The Routledge companion to alternative and community media. London and New York, NY: Routledge.

Bachl, M. (2018). (Alternative) media sources in AfDcentered Facebook discussions. Studies in Communication / Media, 7(2), 256-270.

Dagron, A. G. (2007). Call me impure: Myths and paradigms of participatory communication. In L. K. Fuller (Ed.), The power of global community media (pp. 197-207). New York, NY: Palgrave Macmillan US. https://doi.org/10.1007/978-1-137-01625-6_18

Downing, J. (2001). Radical media: Rebellious communication and social movements. Thousand Oaks, CA: Sage.

Downing, J. D. H. (2003). Audiences and readers of alternative media: The absent lure of the virtually unknown. Media, Culture \& Society, 25(5), 625-645. https://doi.org/10.1177/01634437030255004

Edgerly, S. (2017). Seeking out and avoiding the news media: Young adults' proposed strategies for obtaining current events information. Mass Communication and Society, 20(3), 358-377. https://doi.org/ 10.1080/15205436.2016.1262424

Fenton, N., \& Downey, J. (2003). Counter public spheres and global modernity. Javnost: The Public, 10(1), 15-32. https://doi.org/10.1080/13183222. 2003.11008819

Figenschou, T. U., \& Ihlebæk, K. A. (2019). Challenging journalistic authority: Media criticism in farright alternative media. Journalism Studies, 20(9), 1221-1237. https://doi.org/10.1080/1461670X. 2018.1500868

Fuchs, C. (2010). Alternative media as critical media. European Journal of Social Theory, 13(2), 173-192. https://doi.org/10.1177/1368431010362294

Goodman, L. A. (2011). Comment: On respondentdriven sampling and snowball sampling in hard-toreach populations and snowball sampling not in hard-to-reach populations. Sociological Methodology, 41(1), 347-353. https://doi.org/10.1111/j.14679531.2011.01242.x

Hájek, R., \& Carpentier, N. (2015). Alternative mainstream media in the Czech Republic: Beyond the dichotomy of alterative and mainstream media. Continuum, 29(3), 365-382. https://doi.org/10.1080/ 10304312.2014.986061

Haller, A., \& Holt, K. (2019). Paradoxical populism: How PEGIDA relates to mainstream and alternative media. Information, Communication \& Society, 22(12), 1665-1680. https://doi.org/10.1080/ 1369118X.2018.1449882

Haller, A., Holt, K., \& de la Brosse, R. (2019). The 'other' alternatives: Political right-wing alternative media. Journal of Alternative and Community Media, 4(1),
1-6. https://doi.org/10.1386/joacm_00039_2

Holt, K. (2018). Alternative media and the notion of anti-systemness: Towards an analytical framework. Media and Communication, 6(4), 49. https://doi.org/ 10.17645/mac.v6i4.1467

Holt, K. (2019). Right-wing alternative media. London and New York, NY: Routledge.

Holt, K. (2020). Populism and alternative media. In B. Krämer \& C. Holtz-Bacha (Eds.), Perspectives on populism and the media (pp. 201-214). Baden-Baden: Nomos.

Holt, K., Ustad Figenschou, T., \& Frischlich, L. (2019). Key dimensions of alternative news media. Digital Journalism, 7(7), 860-869. https://doi.org/10.1080/ 21670811.2019.1625715

Jackob, N. (2010). No alternatives? The relationship between perceived media dependency, use of alternative information sources, and general trust in mass media. International Journal of Communication, 4, 589-606.

Kaun, A., \& Uldam, J. (2017). Digital activism: After the hype. New Media \& Society, 20(6), 2099-2106. https://doi.org/10.1177/1461444817731924

Kenix, L. J. (2011). Alternative and mainstream media: The converging spectrum. London: Bloomsbury.

Krämer, B. (2018). Populism, media, and the form of society. Communication Theory, 28(4), 444-465. https:// doi.org/10.1093/ct/qty017

Kristensen, G. K., \& Ravn, M. N. (2015). The voices heard and the voices silenced: Recruitment processes in qualitative interviews studies. Qualitative Research, 15(6), 722-737. https://doi.org/10.1177/ 1468794114567496

Leung, D. K. K., \& Lee, F. L. F. (2014). Cultivating an active online counterpublic: Examining usage and political impact of Internet alternative media. The International Journal of Press/Politics, 19(3), 340-359. https:// doi.org/10.1177/1940161214530787

Marwick, A. E., \& Lewis, R. (2017). Media manipulation and disinformation online. New York, NY: Data \& Society Research Institute. Retrieved from https://datasociety.net/pubs/oh/DataAndSociety_ MediaManipulationAndDisinformationOnline.pdf

Mazzoleni, G. (2008). Populism and the media. In D. Albertazzi \& D. McDonnell (Eds.), Twenty-first century populism (pp. 49-64). London: Palgrave Macmillan UK. https://doi.org/10.1057/9780230592100_4

Müller, P., \& Schulz, A. (2019). Alternative media for a populist audience? Exploring political and media use predictors of exposure to Breitbart, Sputnik, and Co. Information, Communication \& Society. Advance online publication. https://doi.org/ 10.1080/1369118X.2019.1646778

Munn, L. (2019). Alt-right pipeline: Individual journeys to extremism online. First Monday, 24(6).

Newman, N., Fletcher, R., Kalogeropoulos, A., Levy, D., \& Nielsen, R. K. (2018). Reuters institute digital news report 2018. Oxford: Reuters Institute for the Study 
of Journalism.

Noppari, E., Hiltunen, I., \& Ahva, L. (2019). User profiles for populist counter-media websites in Finland. Journal of Alternative and Community Media, 4(1), 23-37.

O'Callaghan, D., Greene, D., Conway, M., Carthy, J., \& Cunningham, P. (2015). Down the (white) rabbit hole: The extreme right and online recommender systems. Social Science Computer Review, 33(4), 459-478. https://doi.org/10.1177/0894439314555329

Phillips, W. (2015). This is why we can't have nice things: Mapping the relationship between online trolling and mainstream culture. Cambridge, MA, and London: The MIT Press.

Phillips, W., \& Milner, R. M. (2017). The ambivalent Internet: Mischief, oddity, and antagonism online. Cambridge: Polity.

Postill, J. (2008). Localizing the Internet beyond communities and networks. New Media \& Society, 10(3), 413-431.

Quandt, T. (2018). Dark participation. Media and Communication, 6(4), 36-48. https://doi.org/10.17645/ mac.v6i4.1519

Rauch, J. (2007). Activists as interpretive communities: Rituals of consumption and interaction in an alternative media audience. Media, Culture \& Society, 29(6), 994-1013. https://doi.org/10.1177/ 0163443707084345

Rauch, J. (2015). Exploring the alternative-mainstream dialectic: What "alternative media" means to a hybrid audience. Communication, Culture \& Critique, 8(1), 124-143. https://doi.org/10.1111/cccr.12068

Rauch, J. (2016). Are there still alternatives? Relationships between alternative media and mainstream media in a converged environment: Reconceiving alternative and mainstream media. Sociology Compass, 10(9), 756-767. https://doi.org/10.1111/soc4.
12403

Schrøder, K. C. (2019). Audience reception research in a post-broadcasting digital age. Television \& New Media, 20(2), 155-169. https://doi.org/10.1177/ 1527476418811114

Schwarzenegger, C. (2020). Personal epistemologies of the media: Selective criticality, pragmatic trust, and competence-confidence in navigating media repertoires in the digital age. New Media \& Society, 22(2), 361-377. https://doi.org/10.1177/14614448 19856919

Schweiger, W. (2017). Der (des)informierte Bürger im Netz [The disinformed citizen in the web]. Springer: Wiesbaden.

Sundar, S. S., \& Limperos, A. M. (2013). Uses and Grats 2.0: New gratifications for new media. Journal of Broadcasting \& Electronic Media, 57(4), 504-525. https://doi.org/10.1080/08838151.2013.845827

Tandoc, E. C., Ling, R., Westlund, O., Duffy, A., Goh, D., \& Zheng Wei, L. (2017). Audiences' acts of authentication in the age of fake news: A conceptual framework. New Media \& Society, 20(8), 2745-2763. https://doi. org/10.1177/1461444817731756

Topinka, R. J. (2018). Politically incorrect participatory media: Racist nationalism on r/ImGoingToHellForThis. New Media \& Society, 20(5), 2050-2069. https://doi.org/10.1177/14614448177 12516

Treré, E. (2016). The dark side of digital politics: Understanding the algorithmic manufacturing of consent and the hindering of online dissidence. IDS Bulletin, 41(1), 127-138. https://doi.org/10.19088/ 1968-2016.1

Treré, E. (2020). Hybrid, media, activism: Ecologies, imaginaries, algorithms. London and New York, NY: Routledge.

\section{About the Author}

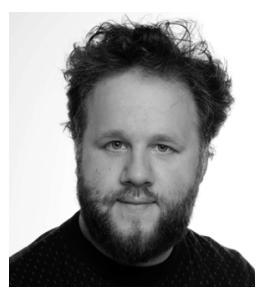

Christian Schwarzenegger (PhD) is a Researcher and Lecturer (Akademischer Rat) at the University of Augsburg, Germany, and from October 2020 to June 2021 a Visiting Professor at the University of Salzburg, Austria. His research interests include the impact of digital transformation on culture and society with an emphasis on everyday life and participation in the digital society. Christian has recently published his research in journals such as New Media and Society, Digital Journalism, and Convergence. 